\title{
Structural visualization of the p53/RNA polymerase II assembly
}

\author{
Sameer K. Singh, ${ }^{1}$ Zhen Qiao, ${ }^{1}$ Lihua Song, ${ }_{1}^{1}$ Vijay Jani ${ }^{1}$ William Rice, ${ }^{2}$ Edward Eng, ${ }^{2}$ \\ Robert A. Coleman, ${ }^{1}$ and Wei-Li Liu ${ }^{1}$ \\ ${ }^{1}$ Gruss-Lipper Biophotonics Center, Department of Anatomy and Structural Biology, Albert Einstein College of Medicine, Bronx, \\ New York 10461, USA; ${ }^{2}$ New York Structural Biology Center, Manhattan, New York 10027, USA
}

The master tumor suppressor p53 activates transcription in response to various cellular stresses in part by facilitating recruitment of the transcription machinery to DNA. Recent studies have documented a direct yet poorly characterized interaction between $\mathrm{p} 53$ and RNA polymerase II (Pol II). Therefore, we dissected the human p53/Pol II interaction via single-particle cryo-electron microscopy, structural docking, and biochemical analyses. This study reveals that 553 binds Pol II via the Rpb1 and Rpb2 subunits, bridging the DNA-binding cleft of Pol II proximal to the upstream DNA entry site. In addition, the key DNA-binding surface of p53, frequently disrupted in various cancers, remains exposed within the assembly. Furthermore, the p53/Pol II cocomplex displays a closed conformation as defined by the position of the Pol II clamp domain. Notably, the interaction of p53 and Pol II leads to increased Pol II elongation activity. These findings indicate that p53 may structurally regulate DNA-binding functions of Pol II via the clamp domain, thereby providing insights into p53-regulated Pol II transcription.

[Keywords: RNA polymerase II; p53; transcription; structure; cryo-electron microscopy]

Supplemental material is available for this article.

Received June 16, 2016; revised version accepted October 18, 2016.

Expression of protein-coding genes mediated by mammalian RNA polymerase II (Pol II) is a highly coordinated and elaborate process (Levine et al. 2014). To precisely transcribe a gene, Pol II must assemble at the transcription start site (TSS) of the promoter along with a host of additional factors to form the preinitiation complex (PIC). The PIC comprises $>85$ polypeptides, including Pol II, Mediator, and the six general transcription factors (GTFs); namely, TFIIA, TFIIB, TFIID, TFIIE, TFIIF, and TFIIH (Roeder 1996; Levine et al. 2014). The process of PIC formation in the absence of transcriptional activators is generally inadequate in response to various environmental cues (Maston et al. 2012). To overcome this inefficiency, transcriptional activators stimulate PIC assembly to promote transcription upon stimuli (Ptashne and Gann 1997; Beckerman and Prives 2010). A key factor among these activators is the p53 tumor suppressor protein. p53 activates vast gene networks to maintain genomic stability by regulating diverse cellular processes such as DNA repair, cell cycle arrest, and apoptosis (Menendez et al. 2009; Bieging et al. 2014). p53 is rapidly activated upon exposure to a variety of stress signals, including DNA damage, oncogene activation, hypoxia, and oxidative stress (Carvajal and Manfredi 2013; Bieging et al. 2014). Not surprisingly, p53 plays a central role in tumor suppression.

Corresponding author: wei-li.liu@einstein.yu.edu Article published online ahead of print. Article and publication date are online at http://www.genesdev.org/cgi/doi/10.1101/gad.285692.116.
This is further highlighted by a battery of evidence showing that $\mathrm{p} 53$ is inactivated by mutations in $~ 50 \%$ of human cancers (Joerger and Fersht 2010; Freed-Pastor and Prives 2012; Bieging et al. 2014). Hence, it is important to understand the molecular mechanism underlying how p53 regulates gene expression, which maintains cell integrity and prevents transformation into a cancerous state.

p53 binds consensus sequences on target gene promoters to directly activate transcription (Menendez et al. 2009). Thus far, p53 has been shown to directly bind and recruit several components of the transcription initiation machinery (e.g., Mediator, TFIIB, TFIID, and TFIIH) to synergistically promote PIC assembly on the promoter (Liu and Berk 1995; Espinosa et al. 2003; Li et al. 2007; Di Lello et al. 2008; Okuda et al. 2008; Liu et al. 2009; Meyer et al. 2010). The interactions of p53 with multiple components of the PIC are thus crucial for transcription initiation. Previous structural studies using advanced single-particle electron microscopy (EM) have begun to reveal the direct interaction of p53 with Mediator or TFIID, featuring distinct structural changes specifically induced by p53 (Liu et al. 2009; Meyer et al. 2010). However, the structural insights into how transcriptional

(C) 2016 Singh et al. This article is distributed exclusively by Cold Spring Harbor Laboratory Press for the first six months after the full-issue publication date (see http://genesdev.cshlp.org/site/misc/terms.xhtml). After six months, it is available under a Creative Commons License (Attribution-NonCommercial 4.0 International), as described at http://creativecommons.org/licenses/by-nc/4.0/. 
activators (e.g., p53 in this study) bind additional PIC components remain limited, largely due to several challenges, including dynamic interactions and inherent protein flexibility (Levine et al. 2014).

Little is also known about the direct role of p53 in the regulation of Pol II activities such as PIC assembly and elongation. A recent elegant high-resolution genomewide study on p53's binding to target genes uncovered that Pol II and p53 were in close proximity to its response elements under a variety of stresses (Chang et al. 2014). Furthermore, biochemical studies in yeast documented an enrichment of Pol II on target genes in the presence of p53 (Kim et al. 2011). Importantly, a direct association between Pol II and p53's core DNA-binding domain was observed (Kim et al. 2011). These findings suggest that p53 directly or indirectly mediates Pol II recruitment to govern transcription in response to stimuli. Therefore, we hypothesize that p53 directly binds Pol II to structurally aid in its recruitment to DNA and modulate transcription activity. Understanding the detailed structural mechanism of the p53/Pol II interaction will shed light on how p53 regulates Pol II activity for gene expression. Furthermore, it will be intriguing to structurally dissect p53's ability to efficiently recruit multiple factors during PIC assembly.

As the first step to address these pivotal questions, we developed a strategy to generate sufficient amounts of the p53/Pol II cocomplex, which allowed us to determine the three-dimensional (3D) structure using single-particle cryo-EM. The structure of the assembly reveals that p53 binds Pol II over the DNA-binding cleft proximal to the upstream DNA entry site through distinct contacts with the Rpb1 and Rpb2 subunits. We further corroborated these observations by photoactivable protein cross-linking label transfer assays. In addition, p53-bound Pol II displays a closed conformation, as defined by the narrow position of the Pol II clamp domain. Docking analysis further suggests that $\mathrm{p} 53$ 's central DNA contact interface, frequently altered in a variety of cancer patients (FreedPastor and Prives 2012), is exposed within the p53/Pol II assembly. Notably, we investigated the potential functional impact of their direct interaction on Pol II elongation activity via in vitro elongation/exonuclease III (Exo III) mapping assays. Our work demonstrates that p53's binding increases Pol II elongation activity. These integrated studies begin to provide new insights into the regulation of p53 on the DNA-binding and transcription activities of RNA Pol II.

\section{Results}

\section{The assembly of p53 and RNA Pol II}

Previous biochemical studies revealed a direct association between human p53 and yeast Pol II (Balakrishnan and Gross 2008; Kim et al. 2011). As a first step toward structurally dissecting the interaction between mammalian Pol II and p53, we set out to assemble the human p53/ Pol II cocomplex in vitro (Fig. 1). To obtain p53/Pol II cocomplexes for cryo-EM studies, we modified our Pol II immunopurification protocol to permit p53 loading (Fig.

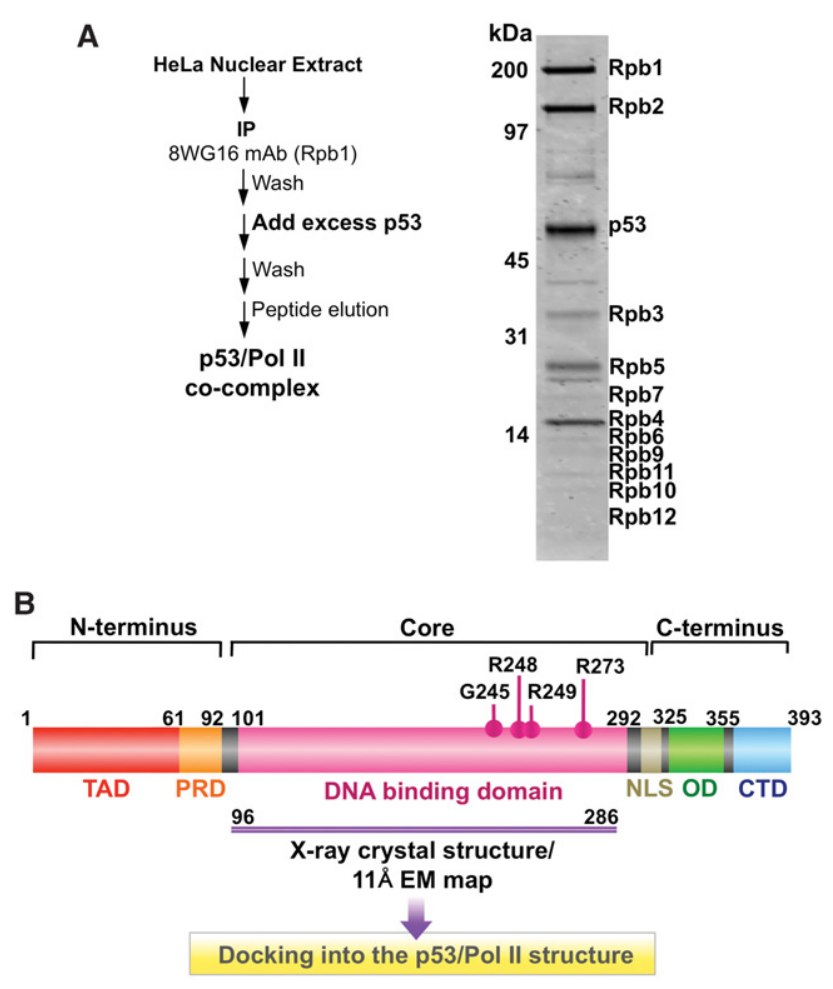

Figure 1. Purification and biochemical analysis of the p53/Pol II protein cocomplex. (A) Schematic representation of the strategy used to purify the binary human p53/Pol II cocomplex. Pol II was first immunoprecipitated using a monoclonal antibody $(\mathrm{mAb})$ against the C-terminal domain (CTD) of the Rpb1 subunit. After extensive washing, a fivefold molar excess of p53 was added to the resins containing Pol II. A homogeneous stable p53/Pol II cocomplex was obtained after extensive washes followed by an elution step using a specific peptide against the CTD of Rpb1. The cocomplex was analyzed by $4 \%-12 \%$ SDS-PAGE and visualized by Flamingo fluorescent gel stain (Bio-Rad) and a Typhoon image scanning system (GE). (B) Schematic representation of the domain structure of $\mathrm{p} 53$. Delineation of the transcription activation domain ( $T A D$; red), proline-rich domain (PRD; orange), DNA-binding domain (pink), nuclear localization signal (NLS; silver), oligomerization domain (OD; green), and C-terminal regulatory domain (CTD; light blue) are presented (Freed-Pastor and Prives 2012). The approximate locations of the four key residues for DNA binding within the core domain are indicated. These four residues occur as hot spot cancer mutations in $20 \%$ of cancer patients. The crystal structure of the human $\mathrm{p} 53$ protein spanning the core DNA-binding domain (Protein Data Bank [PDB] ID 2OCJ) (Wang et al. 2007) was docked into our p53/Pol II structure.

1A). In addition, the human full-length wild-type p53 protein was used and is represented in Figure 1B to structurally visualize the direct interaction between p53 and Pol II in their native forms. Briefly, we carried out highly specific immunoprecipitation of Pol II from fractionated HeLa nuclear extracts using a monoclonal antibody against the Rpb1 subunit of Pol II. Pol II-bound resins were washed extensively to remove loosely associated and nonspecifically bound proteins and then coincubated with a fivefold molar excess of p53. Unbound p53 was removed from the affinity resin by extensive washing. The cocomplex was 
eluted from the affinity column using a specific competitor peptide recognized by the Rpb1 antibody. The eluted p53-bound Pol II was analyzed by SDS-PAGE/Flamingo staining and designated as p53/Pol II (Fig. 1A, right panel). A coimmunoprecipitation assay and Western blot analysis were also performed to confirm the association between p53 and Pol II (Supplemental Fig. S1).

\section{$3 D$ reconstruction of the $p 53 /$ Pol II cocomplex}

Currently, no 3D structures have been reported for activators bound to Pol II. Previous structural studies have established that p53's binding to large basal transcription factors, such as TFIID and Mediator, introduces specific structural features to the cocomplex (Liu et al. 2009; Meyer et al. 2010). It is unclear whether p53 structurally regulates Pol II in a similar manner. Thus, we used singleparticle cryo-EM to determine how p53 binds Pol II and whether p53 induces distinct structural features within Pol II. To maintain the native, biologically relevant state of the cocomplex, we chose not to cross-link our p53/Pol II samples for acquisition of cryo-EM images. Since our samples were not cross-linked, heterogeneity (i.e., p53bound Pol II vs. unbound Pol II) occurred in the data set (see the Materials and Methods). This was consistent with a previous study showing heterogeneity resulting from a mixture of free Pol II and DNA-bound Pol II (Bernecky et al. 2016). To help define potential extra density within the assembly, we performed a control 3D analysis of our Pol II preparations lacking p53, generated exactly as in Figure 1A, and further compared it with previously published Pol II structures (Supplemental Fig. S2).

To circumvent potential model bias, we also generated a reference-free initial model of p53/Pol II by applying the random conical tilt (RCT) approach (Radermacher et al. 1987) followed by the unsupervised 3D classification with the entire data set via RELION (regularized likelihood optimization) (Supplemental Fig. S3; Scheres 2012). The 3D reconstruction of p53/Pol II at $\sim 11 \AA$ global resolution displays signature features of Pol II, including the stalk, clamp, and lobe (Fig. 2A; Supplemental movie S1). By docking atomic models of human and bovine Pol IIs (Protein Data Bank [PDB] ID 5IY7 and 5FLM) (Bernecky et al. 2016; He et al. 2016) into our 3D reconstruction, prominent extra densities absent from Pol II structures were defined and thereby assigned to represent the p53 protein. The structure reveals that p53 targets distinct surfaces within Pol II via the Rpb1 and Rpb2 subunits. In addition, p53 is positioned over the DNA-binding cleft (Bernecky et al. 2016). p53 binds adjacent to the protrusion domain of the Rpb2 subunit close to the region where the upstream DNA entry site resides (Fig. 2A). In particular, p53 binds a distinct region of Rpb1, which predominantly forms the clamp domain that is responsible for the open/ closed conformation of Pol II (Kostek et al. 2006). Therefore, to clarify which Pol II form was primarily represented when bound to p53, our structure was superimposed with the open/closed state of Pol II (Fig. 2B). p53-bound Pol II clearly displayed a closed conformation, as determined by narrowing of the clamp.
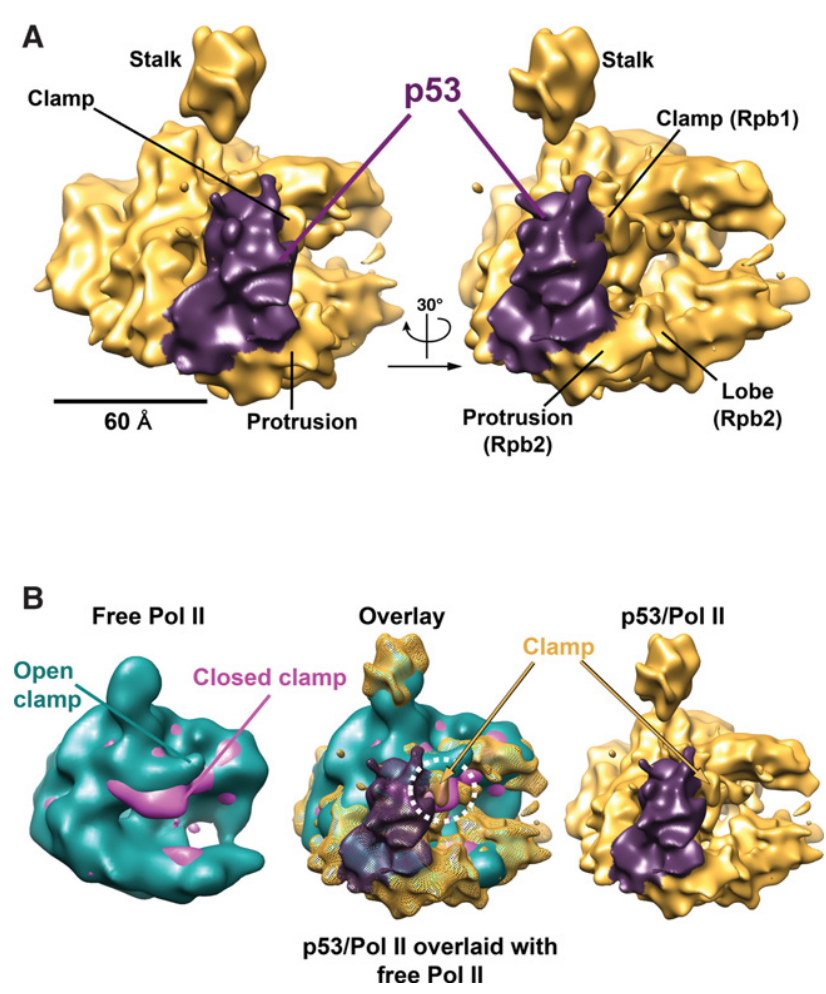

Figure 2. The cryo-EM 3D structure of the p53/Pol II cocomplex. (A) 3D reconstruction of p53/Pol II ( 11 $\AA$ ) is shown in two different views. The prominent extra EM density between the p53/Pol II and Pol II-alone maps is defined as the $\mathrm{p} 53$ protein (highlighted in dark purple). Pol II is colored gold, with canonical structural features of Pol II indicated. Bar, $60 \AA$. (B, left panel) The 3D structures of published Pol II display open and closed clamps (highlighted in blue and pink, respectively) (Kostek et al. 2006). The 3D reconstruction of p53/Pol II was superimposed onto free Pol II structures using Chimera (Pettersen et al. 2004). The clamp domain of p53/Pol II (shown in gold mesh) that overlaps with the closed conformation of free Pol II (pink) is indicated by the white circle. The correlation score for the fitting of the closed Pol II form and p53/Pol II is 0.9626 , and the correlation score for the open Pol II form versus p53/Pol II is 0.9574 (Chimera). The p53 density is highlighted in purple.

Given the inherent structural flexibility of the $\mathrm{N}$ terminus and C terminus of p53, we suspected that the EM density observed would most likely represent the core sequence-specific DNA-binding domain of p53. In support of this hypothesis, a previous biochemical report documented the direct association of Pol II and the p53 core domain (Balakrishnan and Gross 2008; Kim et al. 2011). To test this idea, we docked a crystal structure of p53's core DNA-binding domain into our reconstruction (Fig. 3). First, we generated an $\sim 11 \AA$ EM map from the crystal structure of one p53 core domain (PDB ID 2OCJ) (Wang et al. 2007) to assist the orientation of the docking. After the position was defined, the crystal structure was docked into the density map of the p53/Pol II cocomplex via flexible fitting using iMODFit (Fig. 3; Supplemental Fig. S4; Lopez-Blanco and Chacon 2013). The analysis shows that a single DNA-binding domain accounts for a majority 


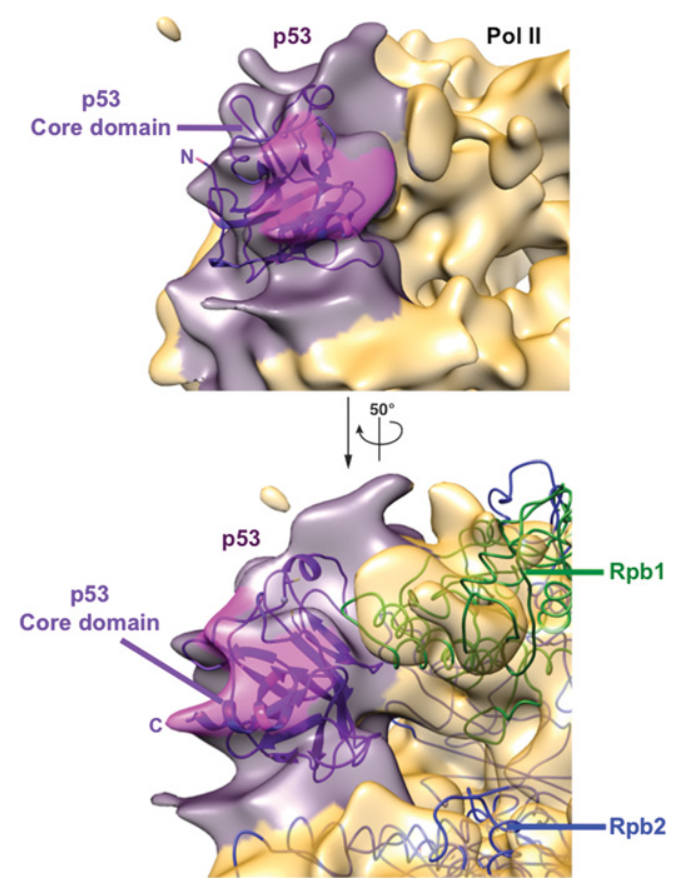

Figure 3. p53's DNA-binding interface is exposed within the assembly. Docking of the crystal structure of the human p53 core DNA-binding domain (dark purple; PDB ID 2OCJ) (Wang et al. 2007) into the $3 \mathrm{D}$ reconstruction of $\mathrm{p} 53 / \mathrm{Pol}$ II is shown in two different zoomed views. The p53 density is highlighted in light purple, and Pol II is colored in gold. The surface region on the EM map containing four p53 key DNA-binding residues (i.e., G245, R248, $\mathrm{R} 273$, and R280) is highlighted in pink. The $\mathrm{N}$ terminus and $\mathrm{C}$ terminus of the core domain are indicated. The correlation score in iMODFit (Lopez-Blanco and Chacon 2013) for flexible fitting of p53 into the segmented extra density in the p53/Pol II map is 0.87595. (Bottom panel) Docking of human Pol II from the open PIC (PDB ID 5IY7) (He et al. 2016) into our cryo-EM map of p53/Pol II shows no obvious steric clashes between p53 and Rpb1 (green) or Rbp2 (blue).

of the p53 density in our structure, with the flexible $\mathrm{N}$ terminus and $\mathrm{C}$ terminus of $\mathrm{p} 53$ being mostly averaged out during data processing. This finding is consistent with the evidence that the core domain of p53 mediates binding to Pol II (Kim et al. 2011). Furthermore, the docking analysis suggests that p53's key DNA-binding interface can be exposed when bound to Pol II.

To potentially probe the missing density of p53, focused two-dimensional (2D) classification was carried out on select class averages corresponding to the view of p53-bound Pol II (Supplemental Fig. S5). We found no large extra density that could correspond to the $\sim 200$-kDa tetrameric DNA-binding form of $\mathrm{p} 53$. In addition, variability around the p53/Pol II contact surface was detected, indicating structural plasticity of p53's interaction with Pol II. This structural flexibility appeared to limit the visibility and resolution of the p53 density within the $3 \mathrm{D}$ reconstruction. Nevertheless, even though our structure indicates a p53 monomer that is most likely present in the assembly, it is possible that other oligomeric forms of p53 can associate with Pol II.

\section{Biochemical mapping of p53 contact surfaces}

To validate our observations and map potential contact surfaces in the context of intact Pol II, we carried out photo-cross-linking label transfer assays using the trifunctional reagent Sulfo-SBED (S-SBED) (Supplemental Fig. S6), which had been used previously to determine the targets of activators within various transcription complexes (Brown et al. 2001; Neely et al. 2002; Liu et al. 2009). To identify all potential Pol II contacts with p53, we first labeled purified p53 with S-SBED at $\mathrm{pH} \sim 7.9$ to target all internal tertiary amines (i.e., lysines), thereby biasing the reaction toward "body labeling" (Fig. 4, left panel). Previous studies reported that the N-terminal transactivation domain of p53 interacts with basal transcription factors (Liu et al. 1993; Di Lello et al. 2006). We thus also sought to examine which Pol II subunits contacted the N-terminal transactivation domain of $\mathrm{p} 53$. Hence, the $\mathrm{p} 53$ protein was also labeled with S-SBED specifically at $\mathrm{pH} \sim 7.2$, which allows the sulfonated ester group to react primarily with the $\mathrm{N}$-terminal primary amine group, thus achieving an N-terminal labeling (Fig. 4, right panel). With the exception of differential $\mathrm{pH}$ used, the "body-labeling" and "N terminus-labeling" experiments were conducted in

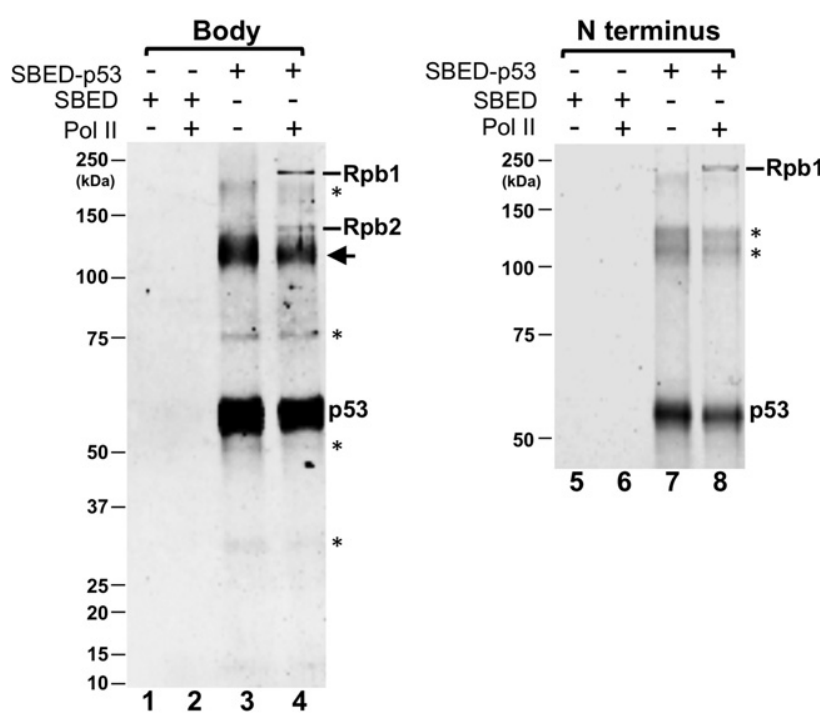

Figure 4. p53 contacts within Pol II using label transfer assays. p53 was labeled at internal lysines (left panel, marked as "body") and the $\mathrm{N}$ terminus (right panel, marked as "N terminus") with the trifunctional S-SBED cross-linker (Thermo Fisher Scientific). Reactions containing cross-linker alone (lanes 1,2,5,6) and labeled p53 (lanes 3,4,7,8) were mixed with Pol II (lanes $2,4,6,8)$ and exposed to UV light. Pol II subunits that are within 17-21 $\AA$ distance of the S-SBED were covalently conjugated to p53. After cleaving the cross-linker with DTT, the biotin group was transferred from p53 to the cross-linked Pol II subunit. SDS-PAGE and immunoblotting with anti-biotin revealed Pol II subunits that specifically contact the p53 protein. The stars represent nonspecific cross-linked bands. The arrow represents cross-linked p53 dimers. Consistent with our previous report (Liu et al. 2009), p53 cross-linked with itself easily due to its oligomerization domain. 
the same manner (Supplemental Fig. S6). Our purified native Pol II was incubated with S-SBED-labeled p53 to initiate formation of the p53/Pol II cocomplex. The samples were then exposed to UV to activate the aryl azide group on S-SBED, which cross-links to nearby subunits of Pol II. After cleavage of the disulfide bond within S-SBED, the biotin moiety was transferred from p53 to any adjacent Pol II subunits within a 17-21 $\AA$ radius (Brown et al. 2001; Neely et al. 2002). The resulting biotin-tagged Pol II subunits were visualized by Western blot analysis using an antibody against biotin.

Our analysis of the p53/Pol II association showed that when we body-labeled the lysines throughout p53, the Rpb1 subunit was strongly tagged with biotin, while Rpb2 was also weakly cross-linked (Fig. 4, left panel, cf. lanes 3 and 4). These specifically cross-linked Pol II subunits migrated according to their known molecular weights (217 kDa and $134 \mathrm{kDa}$, respectively). This result corroborates our structural and docking analysis, which demonstrated that $\mathrm{p} 53$ contacts the Rpb1 and Rpb2 subunits. Intriguingly, our results showed that the N-terminal activation domain of p53 contacts the Rpb1 subunit but not Rpb2 (Fig. 4, right panel, cf. lanes 7 and 8). This would place the $\mathrm{N}$ terminus of $\mathrm{p} 53$ distal to Rpb2. However, the flexibility of p53's N-terminal activation domain prevented its visualization in our structure.

\section{p53 modulates Pol II elongation activity}

While the association between p53 and Pol II was documented previously (Balakrishnan and Gross 2008; Kim et al. 2011) and in this study, the functional activity of their interaction remains poorly understood. To this end, we investigated whether the p53/Pol II assembly had an effect on the elongation activity of Pol II via an in vitro Exo III mapping assay (Fig. 5; Supplemental Fig. S7), as established previously (Sidorenkov et al. 1998; Kireeva et al. 2000). In brief, an elongation complex was formed by loading Pol II onto a fluorescently labeled DNA template with a bubble containing an RNA/DNA hybrid (Fig. 5, top panel; Supplemental Fig. S7). To map out the position of Pol II on the template, Exo III was added to digest the DNA in a $3^{\prime}$-to-5' direction until encountering the elongation complex. These mapping reactions were carried out on Pol II alone (Fig. 5A, lanes 2,3), Pol II preassembled with p53 (Fig. 5A, lanes 4,5, designated as "p53/Pol II"), or Pol II with later addition of p53 (Fig. 5A, lanes 6,7, designated as "Pol II, +p53"). For the location of Pol II specifically loaded onto the template strand, the Exo III digestion reaction yielded a single major product at 143 base pairs (bp), representing loaded Pol II. Once Pol II was loaded onto the bubble, transcription was initiated by adding a mixture of nucleotide triphosphates (NTPs) lacking uridine triphosphate (UTP), which allows Pol II to transcribe $5 \mathrm{bp}$ and stall on the template (Supplemental Fig. S7). Upon NTP (-UTP) addition, Pol II elongation occurred on the template and yielded a 138-bp Exo III digestion product, representing elongated Pol II (Fig. 5A, lanes $3,5,7)$. The elongation efficiency was then determined based on the intensity of the 138-bp band relative
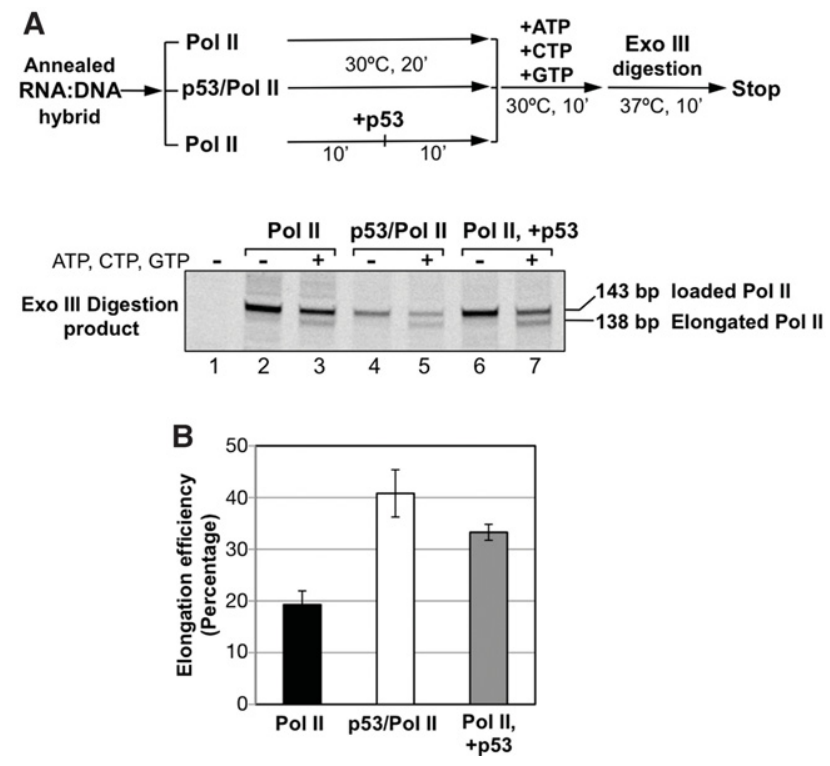

Figure 5. p53/Pol II assembly affects Pol II elongation via Exo III mapping. (A) DNA templates with a bubble containing an RNA: DNA hybrid were mixed together with Pol II alone (lanes 2,3) or a preassembled p53/Pol II complex (lanes 4,5) and incubated for 20 min at $30^{\circ} \mathrm{C}$. (Lanes 6,7) A third set of reactions (i.e., Pol II, + p53) contained Pol II incubated with the RNA:DNA hybrid template for $10 \mathrm{~min}$ at $30^{\circ} \mathrm{C}$ followed by addition of p53 for another $10 \mathrm{~min}$. (Lanes 3,5,7) Elongation of Pol II was initiated with a mixture of NTPs lacking UTP for $10 \mathrm{~min}$ at $30^{\circ} \mathrm{C}$, resulting in Pol II stalling $5 \mathrm{bp}$ downstream at a $\mathrm{T}$ residue in the template. Exo III digestion was carried out for $10 \mathrm{~min}$ at $37^{\circ} \mathrm{C}$ to map out the position of Pol II on the template in the absence and presence of NTPs. The 143-bp digestion product signifies Pol II loaded onto the $3^{\prime}$ of the RNA:DNA hybrid, while the 138-bp band represents elongated Pol II. (B) Quantitation of the percentage of elongated Pol II represents the intensity of the 138-bp band divided by the sum intensity of the 138-bp band and the 143-bp band. At least six independent experiments were performed and yielded standard deviations as indicated.

to the sum intensity of both the 138-bp and 143-bp bands (i.e., loaded plus elongated Pol IIs) (Fig. 5B). When Pol II was preassembled with $\mathrm{p} 53$, the relative percentage of elongation was increased compared with Pol II alone. An elevated elongation efficiency of Pol II was also observed in the presence of p53 after Pol II was loaded. These results indicate that $\mathrm{p} 53$ 's binding can modulate the elongation activity of Pol II.

In addition to elongation activity, some mild differences in the loading of Pol II onto the bubble were also consistently detected (Fig. 5A, cf. lanes 2, 4, and 6). Preassembly of p53/Pol II slightly inhibited Pol II loading onto the RNA/DNA hybrid template (Fig. 5A, cf. lanes 2 and 4). On the other hand, Pol II loading was not affected when p53 was subsequently added (Fig. 5A, cf. lanes 2 and 6). This finding indicates that the p53/Pol II association may affect engagement of Pol II with the RNA/DNA bubble. Perhaps the preassembly of p53 on Pol II might inhibit nonspecific loading of the DNA into the Pol II cleft in the absence of additional core promoter recognition factors. 
Collectively, our structural and biochemical findings reveal that p53 targets distinct surfaces of Pol II to regulate its conformational state and elongation function, thereby providing insights into p53-mediated gene expression for tumor suppression.

\section{Discussion}

Our studies reveal that p53 specifically targets distinct surfaces of Pol II that engage DNA. p53 appears to contact Rpb1 via the clamp domain and Rpb2 via the lobe and protrusion domains (Fig. 2). These domains form part of the cleft intricately involved in Pol II/DNA interactions. The clamp domain directs open and closed conformations of Pol II responsible for its specific functions (Kostek et al. 2006). The open conformation functions to accommodate DNA into the Pol II cleft (Chakraborty et al. 2012; He et al. 2013). The closed conformation stabilizes the interaction of Pol II with nucleic acids during transcription initiation and elongation (Gnatt et al. 2001; Kostek et al. 2006; Chakraborty et al. 2012; Bernecky et al. 2016). Here, a closed conformation was observed when p53 bound to Pol II (Fig. 2B). In addition, p53 aids in Pol II elongation efficiency (Fig. 5). Another study using a yeast system suggests that p53 inhibits Pol II processivity on episomal reporter genes (Kim et al. 2011). These findings indicate that p53 could directly modulate Pol II's clamp domain to regulate transcription initiation and elongation. In support of this idea, the elongation factor Spt4/5 targets the same position on the Pol II cleft as p53, displaying a closed conformation within the context of an elongation complex (Gnatt et al. 2001; Kostek et al. 2006; Bernecky et al. 2016). Importantly, Spt4/5 directly interacts with the clamp domain to both positively and negatively regulate Pol II elongation (Yamaguchi et al. 1999; Bernecky et al. 2016; Crickard et al. 2016).

The docking analysis reveals that p53's key DNA-binding interface, frequently mutated in a variety of cancers (Freed-Pastor and Prives 2012), is exposed on the surface of the assembly (Fig. 3). This indicates that p53 could retain its ability to associate with DNA directly while in complex with Pol II. Perhaps this ability could allow p53 to mimic elongation factors Spt4/5 and NusG, which stabilize the upstream DNA and the nontemplate strand in the transcription bubble to help prevent Pol II backtracking (Herbert et al. 2010; Chakraborty et al. 2012; Bernecky et al. 2016; Crickard et al. 2016). Therefore, a conserved structural mechanism may be used by p53, Spt4/5, and NusG to modulate Pol II elongation activity. An important and challenging next step will be to pursue cryoEM-derived p53/Pol II/DNA structures. It will be intriguing to ascertain whether these p53-induced changes can accommodate or even facilitate DNA contacts that may stabilize the binding of Pol II to DNA and/or the transcription bubble.

Recent elegant structural studies using advanced single-particle cryo-EM have begun to reveal the relative arrangements between Pol II and the basal factors within the PIC (He et al. 2013, 2016; Murakami et al. 2015; Plaschka et al. 2015; Louder et al. 2016). However, the structural insights into how transcriptional activators (e.g., p53 in this study) bind human Pol II and the PIC components remain limited largely due to several challenges, including dynamic interactions and inherent protein flexibility (Levine et al. 2014). Therefore, we docked our 3D structure into atomic models of the nearly complete human closed and open PICs (Fig. 6; Supplemental Fig. S8A; Supplemental Movies S2, S3; He et al. 2016). These docking experiments reveal that p53 would occupy a distinct surface of Pol II near the core promoter DNA between the TSS and the upstream elements (e.g., TATAbox and BRE). However, the p53 density appears to overlap with DNA in this region. Since structural variability occurs when p53 binds Pol II, p53's position is likely dynamic (Supplemental Fig. S5). Perhaps, to accommodate the upstream DNA, p53 could adjust its location accordingly within the PIC. The variability of p53's contact surface within Pol II implies the potential flexibility of p53 to
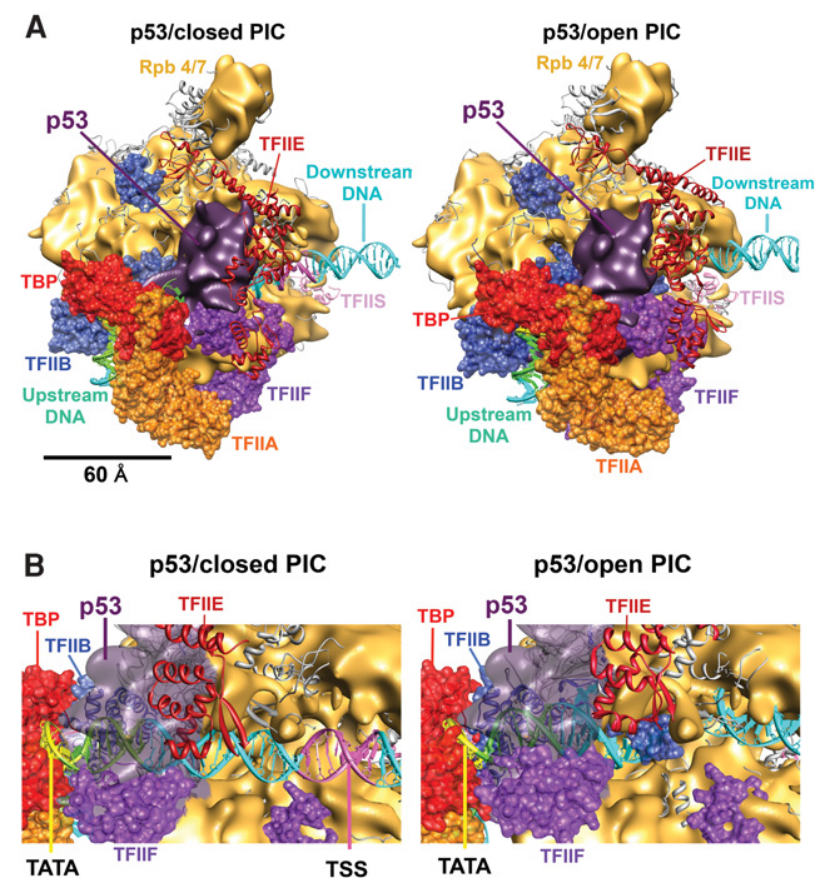

Figure 6. Representative computational models of p53's multiplex interactions within the core PICs. $(A)$ Docking of our cryoEM structure of the p53/Pol II cocomplex into atomic models derived from the high-resolution $3 \mathrm{D}$ reconstructions of the closed and open human PICs (PDB ID 5IY6 and 5IY7) (He et al. 2016) is shown. The EM density representing p53 is highlighted in dark purple, while Pol II is colored gold. Components within this core PIC are color-coded as in He et al. (2016). p53 could potentially reorientate during the transition between the open and closed PICs. (B) Rotated and zoomed views display the location of p53 with respect to DNA and the adjacent components within the core closed PIC (left panel) and open PIC (right panel). TFIIE- $\beta$ is omitted for clarity. The TATA-box (TATA, yellow) and TSS (pink) within the core promoter are listed. Analyses imply that p53 likely contacts the TBP subunit (red spheres) of TFIID, TFIIB (blues spheres and ribbons), and upstream promoter DNA during p53/TFIID-mediated PIC assembly. 
engage Pol II and DNA. This unique position indicates that p53 may be involved in the progression of the PIC from a closed to an open state, potentially binding nontemplate DNA strands in the bubble.

Notably, certain target genes harbor the p53 response elements distal to the core promoter (Chang et al. 2014). In these cases, a looping mechanism during transcription activation could be involved. Based on our structure, we speculate that Pol II could bind a p53 monomer or dimer. Perhaps when the p53/RNA Pol II complex encounters a response element, association with additional p53 oligomers may help it to loop and bind the core promoter in a hemispecific manner via contacts within the PIC components. In support of this idea, a previous study suggests that one dimer of p53 occupies the response element, while the other dimer of the tetramer can bind nonspecific DNA (Leith et al. 2012). Additionally, Pol II recruitment could be mediated by p53's interactions with other PIC components such as TFIID and Mediator.

The computational models in Figure 6 also imply that p53 bound to Pol II would be in close proximity to the binding site of the core initiation machinery, specifically the GTFs TFIID and TFIIB, (Geiger et al. 1996; Nikolov et al. 1996; Kostrewa et al. 2009; Muhlbacher et al. 2014). This observation is supported by several lines of evidence. First, both biochemical and structural reports have shown that p53 interacts directly with TFIID (via its TBP and TAF subunits) and TFIIB (Liu et al. 1993, 2009; Martin et al. 1993; Liu and Berk 1995; Bereczki et al. 2008). Second, the N-terminal activation domain of p53 can bind the first helical repeat of TFIIB that is immediately adjacent to p53 present in our docked structure (Jonker et al. 2005; Langlois et al. 2008). Moreover, a recent elegant high-resolution genome-wide mapping study documented that p53, Pol II, and TFIIB are in close proximity at $\mathrm{p} 53$ response elements during stress across different cell lines (Chang et al. 2014). Collectively, these studies imply that p53 could stimulate a core scaffold via multiplex interactions with Pol II, TFIIB, and TBP/ TFIID within the PIC (Liu et al. 2009).

Activators, such as p53, target the Mediator coactivator complex to assist Pol II recruitment on DNA (Maston et al. 2012). Therefore, we also superimposed our p53/Pol II structure onto the yeast Mediator core initiation atomic model (i.e., the cITC-cMed complex) (Supplemental Fig. S8B; Plaschka et al. 2015). We found no steric clashes between p53 and core Mediator components (i.e., cMed), posing the possibility that p53 and Mediator can co-occupy Pol II. In further support of our model, a recent cryo-EM structure of a complete yeast Mediator/PIC further suggests that the flexible Mediator tail domain can swing up close to TBP and the upstream DNA where the activator GCN4 resides (Robinson et al. 2016). We also compared our reconstruction with structures of the human Mediator/Pol II/TFIIF cocomplexes (with or without the activator VP16) (Bernecky et al. 2011; Bernecky and Taatjes 2012). The results indicate that p53's position may not interfere with the interface between Pol II, TFIIF, and Mediator. In addition, a previous report on a human p53/Mediator cocomplex suggests that p53 binds distinct surfaces (i.e., the head to middle section) immediately adjacent to the Pol II-docking pocket within Mediator (Meyer et al. 2010). Taken together, these findings raise a possibility for p53 to simultaneously bind Pol II and Mediator for corecruitment to a target gene promoter.

How full-length wild-type human p53 associates with its binding targets remains inconclusive, in large part due to the inherent structural plasticity of the protein at its N-terminal and C-terminal domains (Okorokov et al. 2006; Emamzadah et al. 2011; Melero et al. 2011; Pham et al. 2012). For instance, p53, along with other potent transcriptional activators (e.g., VP16), contains intrinsically disordered regions that fold upon interaction with different partners (Triezenberg 1995; Dyson and Wright 2005; Jonker et al. 2005; Lee et al. 2009; Park et al. 2011). Here our reference-free $2 \mathrm{D}$ class averages and the $3 \mathrm{D}$ structure of the cocomplex did not reveal a tetrameric DNA-binding form of p53 when bound to Pol II (Fig. 2; Supplemental Fig. S5). Rather, the majority of the p53 density in our structure corresponds to that of a lone p53 DNA-binding domain. This indicates that p53 may interact with Pol II as a monomer in the absence of DNA (Fig. 3). However, the p53 density determined from single-particle reconstructions represents only the most stably associated portion of p53 bound to Pol II. This common situation would invariably lead to underrepresenting the actual size of the protein in a manner not unlike crystal structures of domains with flexible loops that become "invisible" in the crystal structure (Levine et al. 2014). We therefore cannot rule out that oligomeric p53 (e.g., dimer) could be present in our p53/Pol II structure. Thus far, limited evidence has been provided regarding the oligomeric status of p53 when bound to its interactors (Kamada et al. 2016). Therefore, it remains an open question whether the tetrameric form of p53 exclusively binds to its interacting factors. To potentially test this idea, we docked a p53 core tetramer into our structure (Supplemental Fig. S9). The analysis suggests that Pol II could potentially bind tetrameric p53. Nevertheless, it is possible that the interaction of Pol II and the p53 core domain could allosterically regulate p53 oligomerization. Consistent with this concept, intramolecular contacts between p53's DNA-binding core domain and an $\mathrm{N}$-terminal hinge region was shown to influence its oligomeric status (Natan et al. 2011). Despite the potential significance of monomeric p53 bound to Pol II, it is premature to speculate regarding its functional importance. Overall, structurally dissecting p53's multiplex interaction with several basal factors of the PIC on target genes will advance our understanding of how activators stimulate eukaryotic transcription.

\section{Materials and methods}

\section{Purification of p53/Pol II}

Human recombinant full-length p53 protein with a Strep tag II and $6 \times$ histidine tag at the $\mathrm{N}$ terminus (plasmid details available on request) was expressed in Sf9 cells using the baculovirus system and purified over StrepTactin resins (GE Life Sciences) 
according to the manufacturer's protocols. Nuclear extract generated from $32 \mathrm{~L}$ of HeLa cells was incubated overnight at $4^{\circ} \mathrm{C}$ with the 8 WG16 anti-Pol II C-terminal domain (CTD) monoclonal antibody $(\mathrm{mAb})$ covalently conjugated to protein G beads (GE Life Sciences). The 8 WG16 immunoprecipitates were centrifuged at $1000 \mathrm{rpm}$ for $5 \mathrm{~min}$ at $4^{\circ} \mathrm{C}$ followed by extensive washing with $0.5 \mathrm{M} \mathrm{KCl} / \mathrm{HEMG}$ buffer and $0.1 \mathrm{M} \mathrm{KCl} / \mathrm{HEMG}$ buffer (at $\mathrm{pH}$ 7.9, 20 mM HEPES, 0.2 mM EDTA, $2 \mathrm{mM} \mathrm{MgCl}_{2}, 10 \%$ glycerol, $0.05 \%$ NP40, $1 \mathrm{mM} \mathrm{DTT}, 0.5 \mathrm{mM}$ PMSF). A fivefold molar excess of purified p53 was added, and the reaction was first incubated for $5 \mathrm{~min}$ at room temperature and then for $2 \mathrm{~h}$ at $4^{\circ} \mathrm{C}$. The beads were washed five times with $0.1 \mathrm{M} \mathrm{KCl} / \mathrm{HEMG}$ buffer. The p53/Pol II cocomplex was eluted using $1.5 \mathrm{mg} / \mathrm{mL}$ peptide in $0.1 \mathrm{M} \mathrm{KCl} / \mathrm{HEMG}$ recognized by $8 \mathrm{WG} 16$. The eluates were concentrated with a Microcon-50 concentrator (EMD-Millipore). Protein samples were analyzed by $4 \%-12 \%$ SDS-PAGE and visualized by Flamingo fluorescent gel stain (Bio-Rad) and a Typhoon image scanning system (GE Life Sciences).

\section{Cryo-EM and single-particle 3D reconstruction of p53/PollI}

For cryo-EM sample grid preparation, a thin carbon film supported by a 400-mesh carbon-thickened C-flat holey grid with hole diameter $1.2 \mu \mathrm{m}$ and spacing $1.3 \mu \mathrm{m}$ (CF-1.2/1.3-4C, Protochips) was freshly glow-discharged using a high-vacuum evaporator (Denton). The grid was loaded onto a Vitrobot (FEI) that was preset at $100 \%$ humidity and $4{ }^{\circ} \mathrm{C}$ for vitrification of our samples. The assembled p53/Pol II cocomplex (3.5 $\mu \mathrm{L} ; 80 \sim 90 \mathrm{ng}$ in total amount) was applied directly on the grid for $10 \mathrm{sec}$ followed by $5.5 \mathrm{sec}$ of blotting. The sample grid was then washed with $3.5 \%$ trehalose in $0.1 \mathrm{M} \mathrm{KCl} / \mathrm{HEM}$ buffer $(20 \mathrm{mM}$ HEPES, $0.2 \mathrm{mM}$ EDTA, $2 \mathrm{mM} \mathrm{MgCl}_{2}$ at $\mathrm{pH} 7.9$ ) for $10 \mathrm{sec}$, blotted for $5.5 \mathrm{sec}$, and finally frozen in liquid ethane.

Initial cryo-EM data were collected with a JEM-2100F transmission electron microscope (JEOL) operated at $200 \mathrm{KeV}$ with a defocus range of $-0.5 \mu \mathrm{m}$ to $-3.5 \mu \mathrm{m}$. Digital micrographs were collected using a K2 direct electron detector (Gatan) operating in counting mode at a calibrated magnification of 34,014 (1.47 $\AA$ per pixel) and a defocus range of $-0.5 \mu \mathrm{m}$ to $-3 \mu \mathrm{m}$, along with the Leginon data collection software for semiautomated acquisition targeting (Suloway et al. 2005). Twenty-five frame exposures were taken at $0.4 \mathrm{sec}$ per frame (10 sec total exposure time) and a total dose of 41.13 electrons per square angstrom per micrograph. Particles were selected using the CTF parameters of the micrographs that were estimated using CTFFIND3 (Mindell and Grigorieff 2003). After using these images for the initial data analysis, new digital micrographs were collected with a Titan Krios transmission electron microscope (FEI) using a K2 direct electron detector (Gatan) operating in counting mode at a calibrated magnification of 45,455 (1.1 $\AA$ per pixel) and a defocus range of $-0.5 \mu \mathrm{m}$ to $-3 \mu \mathrm{m}$, along with the Leginon data collection software for semiautomated acquisition targeting (Suloway et al. 2005). Fifty frame exposures were taken at $0.2 \mathrm{sec}$ per frame (10 sec total exposure time) and a total dose of 66.80 electrons per square angstrom per micrograph. Particles were selected using the CTF parameters of the micrographs that were estimated using CTFFIND3 (Mindell and Grigorieff 2003).

A total of 1000-2000 homogeneous particles was initially picked manually from micrographs that represented the entire defocus spectrum and was used to generate $2 \mathrm{D}$ class averages in a preliminary $2 \mathrm{D}$ classification run. These initial $2 \mathrm{D}$ class averages were then used as references to pick particles from all micrographs using the autopicking function in RELION (Scheres 2012, 2015). All particles were then used to generate 2D class averages in RELION so that the particles from obvious junk classes could be removed. The remaining particles were applied for the $3 \mathrm{D}$ reconstruction. A total of 16,215 particles was obtained from JEM-2100F/K2-derived micrographs for the initial reconstruction. A total of 14,999 particles was obtained from those images recorded using the Titan Krios cryo-microscope and a K2 detector.

All 3D classification analyses were carried out in RELION (Scheres 2012). To circumvent initial model bias, 3D classification was run using a $60 \AA$ low-pass-filtered initial model of p53/Pol II that was generated using the RCT approach (Supplemental Fig. S3B; Radermacher et al. 1987). Initial 3D reconstruction was carried out using 16,215 particles derived from JEM2100F/K2 images. These analyses helped to resolve the heterogeneity of the data set to distinguish p53-bound Pol II particles from unbound Pol II particles. The p53/Pol II structure obtained after sorting displayed distinct canonical features of Pol II and a prominent extra density assigned as the p53 protein. To further define structural features of $\mathrm{p} 53$, the JEM-2100F-derived structure of p53/Pol II (low-pass-filtered to $60 \AA$ ) was used as an initial model for additional unsupervised $3 \mathrm{D}$ classification analysis using the new 14,999-particle data set obtained from the Krios/K2-derived micrographs (Supplemental Fig. S3B). Two out of three classes were indicative of the p53/Pol II initial structure and were pooled together (8097 particles) and subjected to 3D autorefinement followed by another 3D classification to generate the final p53/Pol II structure at a global resolution of $10.8 \AA$. Resolution of the structure was determined using the RELION software and corresponded to the gold-standard Fourier shell correlation using the 0.143 criterion (Supplemental Fig. S3C). Angular distribution of particle views used in the reconstruction was determined using RELION, and its 3D plot was visualized in Chimera (Supplemental Fig. S3D; Supplemental Movie S4). Local resolution was calculated using the Resmap software package (Supplemental Fig. S3B; Kucukelbir et al. 2014), and figures were generated using University of California at San Francisco Chimera (Pettersen et al. 2004).

\section{Generation of an initial 3D model of p53/Pol II using RCT}

To prevent any initial model bias during $3 \mathrm{D}$ reconstruction, an initial model was generated by the RCT method using the EMAN2 scientific image processing suite (Tang et al. 2007). Micrographs of negatively stained p53/Pol II particles were first recorded at tilts of $0^{\circ}$ and $-50^{\circ}$. The picking of the untilted/tilted particle pairs from the micrographs was carried out using the program e2boxer.py. The 2D class averages of the untilted particles were then yielded using the program e2refine2d.py. The best $2 \mathrm{D}$ class averages showing clear features and representing different views of the p53/Pol II structure were selected for further analysis. RCT reconstructions were generated using the particles from each selected class along with the corresponding tilted particles using the program e2rct.py. The RCT reconstructions were then aligned and averaged to produce an optimal reconstruction, which was then low-pass-filtered to $60 \AA$ and used as the initial reference model for 3D classification in RELION (Supplemental Fig. S3B).

\section{Focused classification of p53}

Focused classification was carried out using the IMagic-4D software (van Heel et al. 1996). All particles that generated the p53/ Pol II 3D structure were first subjected to reference-free 2D classification. Select classes that displayed the characteristic view of p53-bound Pol II were then chosen and resubjected to 2D classification using a $2 \mathrm{D}$ mask segmenting the p53 density. 


\section{Docking of the p53 core domain into the p53/Pol II structure}

An EM density map filtered to $11 \AA$ A was generated from a crystal structure of the p53 core domain (PDB ID 2OCJ) (Wang et al. 2007). This EM density of the p53 core domain, along with its crystal structure, was superimposed onto the p53/Pol II reconstruction via rigid body fitting in Chimera. The prominent extra density representing p53 in the p53/Pol II maps was then segmented in Chimera. We then used this segmented density to perform flexible fitting with the crystal structure of p53 (PDB ID 2OCJ) via iMODFit (Lopez-Blanco and Chacon 2013) with a final correlation of 0.87595 . The RMSD (root mean squared deviation) between the final flexible fit p53 model and the initial p53 crystal structure (PDB ID 2OCJ) was $1.709 \AA$.

\section{Label transfer assays}

One microgram of p53 was incubated with $20 \mu \mathrm{L}$ of nickel resin (Qiagen) prior to addition of the cross-linking reagent S-SBED (Thermo Scientific) following the manufacturer's instructions, which reacts with lysines using $0.1 \mathrm{M} \mathrm{KCl} / \mathrm{HMG}$ buffer (at $\mathrm{pH}$ 7.9, $20 \mathrm{mM}$ HEPES, $2 \mathrm{mM} \mathrm{MgCl}_{2}, 10 \%$ glycerol, $0.1 \% \mathrm{NP} 40$, $0.5 \mathrm{mM}$ PMSF). The $\mathrm{N}$ terminus of p53 was labeled using $0.1 \mathrm{M}$ $\mathrm{KCl} / \mathrm{HMG}$ buffer ( $\mathrm{pH} 7.2)$. As a mock control, $0 \mu \mathrm{g}$ of p53 was incubated with $20 \mu \mathrm{L}$ of nickel resin. The reactions were incubated for $15 \mathrm{~min}$ at room temperature in the dark. Excess unreacted cross-linker was removed via extensive washing. S-SBED-labeled p53 was eluted off the nickel resin with $40 \mu \mathrm{L}$ of elution buffer

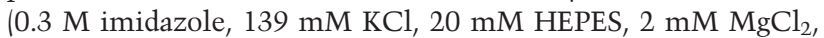
$10 \%$ glycerol, $0.1 \%$ NP40, 0.5 mM PMSF). One-hundred-fifty nanograms of S-SBED-labeled p53 was incubated with $60 \mathrm{ng}$ of Pol II for $1 \mathrm{~h}$ at $30^{\circ} \mathrm{C}$. The mixture was then exposed to UV light $(365 \mathrm{~nm})$ for 10 or $13 \mathrm{~min}$ at room temperature to activate the aryl azide moiety on the SBED-labeled p53 and covalently cross-link any protein within $17-21 \AA$. The reactions were treated with DTT to cleave the disulfide bond and thus transfer the biotin moiety from p53 to the cross-linked subunits of Pol II. The biotinlabeled Poll II subunits were disrupted and detected by SDSPAGE and subjected to immunoblotting using an anti-biotin antibody (Rockland). The identities of biotin-labeled Pol II subunits were determined based on their known migration in SDS-PAGE gels and confirmed by Western blotting analysis using antibodies against the specific Pol II subunits (Santa Cruz Biotechnology).

\section{In vitro elongation/Exo III mapping assays}

The elongation complex containing RNA Pol II bound to a RNA/ DNA hybrid template was formed according to previously established procedures (Sidorenkov et al. 1998; Kireeva et al. 2000) with the following modifications. First, 0.8 pmol of $5^{\prime}$ fluorescently labeled IRDye 800 (IDT)-labeled PCR fragment (258 bp) encompassing the supercore promoter (Revyakin et al. 2012) were mixed together with 125 pmol of a complimentary 10-bp RNA fragment in $\mathrm{ddH}_{2} \mathrm{O}$ and heated for $5 \mathrm{~min}$ to $99^{\circ} \mathrm{C}$. The denatured RNA/DNA mixture was then cooled at a rate of $0.1^{\circ} \mathrm{C}$ per second to $45^{\circ} \mathrm{C}$. The sample remained for an additional minute at $45^{\circ} \mathrm{C}$ followed by a second round of cooling at a rate of $0.1^{\circ} \mathrm{C}$ per second to $25^{\circ} \mathrm{C}$ to allow formation of the RNA/DNA hybrid. p53 (50 nM) was preassembled with $50 \mathrm{nM}$ Pol II for $30 \mathrm{~min}$ at $30^{\circ} \mathrm{C}$ to form the assembly (i.e., p53/Pol II). Next, elongation complexes were assembled by incubating $1.7 \mathrm{nM}$ RNA/DNA template with either $50 \mathrm{nM}$ Pol II or $50 \mathrm{nM}$ preassembled p53/Pol II in $50 \mathrm{mM} \mathrm{KCl} /$ HEMG buffer (at pH 7.9, 12.5 mM HEPES, 0.05 mM EDTA, 6.25 $\mathrm{mM} \mathrm{MgCl} 2,5 \%$ glycerol) for $20 \mathrm{~min}$ at $30^{\circ} \mathrm{C}$. For reactions (i.e., Pol II, +p53) in which p53 was added 10 min after complex formation, p53 was added subsequently for $10 \mathrm{~min}$ at $30^{\circ} \mathrm{C}$. After elon- gation complexes formed, Pol IIs were allowed to transcribe for 5 $\mathrm{bp}$ and then stalled by adding a mixture of NTP containing only ATP, CTP, and GTP (i.e., $50 \mu \mathrm{M} \mathrm{NTP} \mathrm{-UTP)} \mathrm{for} 10 \mathrm{~min}$ at $30^{\circ} \mathrm{C}$.

To map the position of the RNA Pol II complex along the RNA/ DNA template, $50 \mathrm{U}$ of Exo III (New England Biolabs) was added to these reactions for $10 \mathrm{~min}$ at $37^{\circ} \mathrm{C}$. Exo III digestion was then terminated by addition of $2 \times$ sample loading buffer containing formamide (Alfa Aesar) prior to heat denaturation for $3 \mathrm{~min}$ at $70^{\circ} \mathrm{C}$. Reactions, along with fluorescently labeled DNA size standards, were immediately loaded and electrophoresed on a $10 \%$ TBE-urea polyacrylamide gel containing $7 \mathrm{M}$ urea (Invitrogen) followed by fluorescent scanning of the gel (Licor Odyssey). The percentage of elongation efficiency was calculated based on the signal intensity from the 138-bp digestion product divided by the combined signals of the 138-bp and 143-bp fragments. Complete details regarding the sequences of the 258 -bp PCR product and the complementary 10-bp RNA fragment are in the Supplemental Material. At least six independent experiments were performed to yield the standard deviations presented in Figure 5B. Representative data are shown in Figure 5A.

\section{Acknowledgments}

We thank S. Zheng for providing Pol II mAb supernatant, D. King for peptides, and the Tjian laboratory tissue culture facility technicians and all of our laboratory members for helpful advice. We are grateful to M. Keogh, Z. Zhang, and T. Meier for critical comments of the manuscript. We also thank S.M. Shenoy, E. Sylvestre, B. Solly, and A. Contois for high-performance computing cluster technical support. We appreciate assistance from the Analytical Imaging Facility at Albert Einstein College of Medicine, especially F.P. Macaluso, L. Cummins, and G.S. Perumal. We specially thank B. Carragher, C.S. Potter, J. Seitsonen, A. Cheng, C. Wigge, A. Raczkowski, and K. Jordan for helpful suggestions and image acquisition. We thank J. Negron and B. Riley for initial image processing, S. Levy for her early label transfer experiments, and G. Hamilton for programming support. This study was supported by an Albert Einstein College of Medicine start-up fund. Some of this work was performed at the Simons Electron Microscopy Center at the New York Structural Biology Center, which is supported by a grant from the Simons Foundation (grant no. 349247) with additional support from National Institutes of Health (S10 OD019994-01, S10 RR029300-01, S10 RR01729101, and C06 RR017528-01-CEM), the Agouron Institute (grant no. F00316), and Empire State Development's Division of Science, Technology, and Innovation (NYSTAR). W.-L.L. is an affiliated member of the New York Structural Biology Center.

\section{References}

Balakrishnan SK, Gross DS. 2008. The tumor suppressor p53 associates with gene coding regions and co-traverses with elongating RNA polymerase II in an in vivo model. Oncogene 27: 2661-2672.

Beckerman R, Prives C. 2010. Transcriptional regulation by $\mathrm{p} 53$. Cold Spring Harb Perspect Biol 2: a000935.

Bereczki O, Ujfaludi Z, Pardi N, Nagy Z, Tora L, Boros IM, Balint E. 2008. TATA binding protein associated factor 3 (TAF3) interacts with p53 and inhibits its function. BMC Mol Biol 9: 57.

Bernecky C, Taatjes DJ. 2012. Activator-mediator binding stabilizes RNA polymerase II orientation within the human mediator-RNA polymerase II-TFIIF assembly. I Mol Biol 417: 387-394. 
Bernecky C, Grob P, Ebmeier CC, Nogales E, Taatjes DJ. 2011. Molecular architecture of the human Mediator-RNA polymerase II-TFIIF assembly. PLoS Biol 9: e1000603.

Bernecky C, Herzog F, Baumeister W, Plitzko JM, Cramer P. 2016. Structure of transcribing mammalian RNA polymerase II. $\mathrm{Na}$ ture 529: 551-554.

Bieging KT, Mello SS, Attardi LD. 2014. Unravelling mechanisms of p53-mediated tumour suppression. Nat Rev Cancer 14: 359-370.

Brown CE, Howe L, Sousa K, Alley SC, Carrozza MJ, Tan S, Workman JL. 2001. Recruitment of HAT complexes by direct activator interactions with the ATM-related Tral subunit. Science 292: 2333-2337.

Carvajal LA, Manfredi JJ. 2013. Another fork in the road-life or death decisions by the tumour suppressor p53. EMBO Rep 14: 414-421.

Chakraborty A, Wang D, Ebright YW, Korlann Y, Kortkhonjia E, Kim T, Chowdhury S, Wigneshweraraj S, Irschik H, Jansen R, et al. 2012. Opening and closing of the bacterial RNA polymerase clamp. Science 337: 591-595.

Chang GS, Chen XA, Park B, Rhee HS, Li P, Han KH, Mishra T, Chan-Salis KY, Li Y, Hardison RC, et al. 2014. A comprehensive and high-resolution genome-wide response of p53 to stress. Cell Rep 8: 514-527.

Crickard JB, Fu J, Reese JC. 2016. Biochemical analysis of yeast suppressor of Ty $4 / 5(\mathrm{Spt} 4 / 5)$ reveals the importance of nucleic acid interactions in the prevention of RNA polymerase II arrest. J Biol Chem 291: 9853-9870.

Di Lello P, Jenkins LM, Jones TN, Nguyen BD, Hara T, Yamaguchi H, Dikeakos JD, Appella E, Legault P, Omichinski JG. 2006. Structure of the Tfb1/p53 complex: insights into the interaction between the $\mathrm{p} 62 / \mathrm{Tfb} 1$ subunit of TFIIH and the activation domain of p53. Mol Cell 22: 731-740.

Di Lello P, Miller Jenkins LM, Mas C, Langlois C, Malitskaya E, Fradet-Turcotte A, Archambault J, Legault P, Omichinski JG. 2008. p53 and TFIIE $\alpha$ share a common binding site on the Tfb1/p62 subunit of TFIIH. Proc Natl Acad Sci 105: 106-111.

Dyson HJ, Wright PE. 2005. Intrinsically unstructured proteins and their functions. Nat Rev Mol Cell Biol 6: 197-208.

Emamzadah S, Tropia L, Halazonetis TD. 2011. Crystal structure of a multidomain human p53 tetramer bound to the natural CDKN1A (p21) p53-response element. Mol Cancer Res 9: 1493-1499.

Espinosa JM, Verdun RE, Emerson BM. 2003. p53 functions through stress- and promoter-specific recruitment of transcription initiation components before and after DNA damage. Mol Cell 12: 1015-1027.

Freed-Pastor WA, Prives C. 2012. Mutant p53: one name, many proteins. Genes Dev 26: 1268-1286.

Geiger JH, Hahn S, Lee S, Sigler PB. 1996. Crystal structure of the yeast TFIIA/TBP/DNA complex. Science 272: 830-836.

Gnatt AL, Cramer P, Fu J, Bushnell DA, Kornberg RD. 2001. Structural basis of transcription: an RNA polymerase II elongation complex at $3.3 \AA$ A resolution. Science 292: 1876-1882.

He Y, Fang J, Taatjes DI, Nogales E. 2013. Structural visualization of key steps in human transcription initiation. Nature 495: 481-486.

He Y, Yan C, Fang J, Inouye C, Tjian R, Ivanov I, Nogales E. 2016. Near-atomic resolution visualization of human transcription promoter opening. Nature 533: 359-365.

Herbert KM, Zhou J, Mooney RA, Porta AL, Landick R, Block SM. 2010. E. coli NusG inhibits backtracking and accelerates pause-free transcription by promoting forward translocation of RNA polymerase. J Mol Biol 399: 17-30.
Joerger AC, Fersht AR. 2010. The tumor suppressor p53: from structures to drug discovery. Cold Spring Harb Perspect Biol 2: a000919.

Jonker HR, Wechselberger RW, Boelens R, Folkers GE, Kaptein R. 2005. Structural properties of the promiscuous VP16 activation domain. Biochemistry 44: 827-839.

Kamada R, Toguchi Y, Nomura T, Imagawa T, Sakaguchi K. 2016. Tetramer formation of tumor suppressor protein p53: structure, function, and applications. Biopolymers 106: 598-612.

Kim S, Balakrishnan SK, Gross DS. 2011. p53 Interacts with RNA polymerase II through its core domain and impairs Pol II processivity in vivo. PLoS One 6: e22183.

Kireeva ML, Komissarova N, Waugh DS, Kashlev M. 2000. The 8nucleotide-long RNA:DNA hybrid is a primary stability determinant of the RNA polymerase II elongation complex. I Biol Chem 275: 6530-6536.

Kostek SA, Grob P, De Carlo S, Lipscomb JS, Garczarek F, Nogales E. 2006. Molecular architecture and conformational flexibility of human RNA polymerase II. Structure 14: 1691-1700.

Kostrewa D, Zeller ME, Armache KJ, Seizl M, Leike K, Thomm M, Cramer P. 2009. RNA polymerase II-TFIIB structure and mechanism of transcription initiation. Nature 462: 323-330.

Kucukelbir A, Sigworth FJ, Tagare HD. 2014. Quantifying the local resolution of cryo-EM density maps. Nat Methods 11: 63-65.

Langlois C, Mas C, Di Lello P, Jenkins LM, Legault P, Omichinski JG. 2008. NMR structure of the complex between the Tfb1 subunit of TFIIH and the activation domain of VP16: structural similarities between VP16 and p53. I Am Chem Soc 130: 10596-10604.

Lee CW, Arai M, Martinez-Yamout MA, Dyson HJ, Wright PE. 2009. Mapping the interactions of the p53 transactivation domain with the KIX domain of CBP. Biochemistry 48: 2115-2124.

Leith JS, Tafvizi A, Huang F, Uspal WE, Doyle PS, Fersht AR, Mirny LA, van Oijen AM. 2012. Sequence-dependent sliding kinetics of p53. Proc Natl Acad Sci 109: 16552-16557.

Levine M, Cattoglio C, Tjian R. 2014. Looping back to leap forward: transcription enters a new era. Cell 157: 13-25.

Li AG, Piluso LG, Cai X, Gadd BJ, Ladurner AG, Liu X. 2007. An acetylation switch in p53 mediates holo-TFIID recruitment. Mol Cell 28: 408-421.

Liu X, Berk AJ. 1995. Reversal of in vitro p53 squelching by both TFIIB and TFIID. Mol Cell Biol 15: 6474-6478.

Liu X, Miller CW, Koeffler PH, Berk AJ. 1993. The p53 activation domain binds the TATA box-binding polypeptide in HoloTFIID, and a neighboring p53 domain inhibits transcription. Mol Cell Biol 13: 3291-3300.

Liu WL, Coleman RA, Ma E, Grob P, Yang JL, Zhang Y, Dailey G, Nogales E, Tjian R. 2009. Structures of three distinct activator-TFIID complexes. Genes Dev 23: 1510-1521.

Lopez-Blanco JR, Chacon P. 2013. iMODFit: efficient and robust flexible fitting based on vibrational analysis in internal coordinates. I Struct Biol 184: 261-270.

Louder RK, He Y, Lopez-Blanco JR, Fang J, Chacon P, Nogales E. 2016. Structure of promoter-bound TFIID and model of human pre-initiation complex assembly. Nature 531: 604-609.

Martin DW, Munoz RM, Subler MA, Deb S. 1993. p53 binds to the TATA-binding protein-TATA complex. I Biol Chem 268: 13062-13067.

Maston GA, Landt SG, Snyder M, Green MR. 2012. Characterization of enhancer function from genome-wide analyses. Annu Rev Genomics Hum Genet 13: 29-57.

Melero R, Rajagopalan S, Lazaro $M$, Joerger AC, Brandt $T$, Veprintsev DB, Lasso G, Gil D, Scheres SH, Carazo JM, et al. 
2011. Electron microscopy studies on the quaternary structure of p53 reveal different binding modes for p53 tetramers in complex with DNA. Proc Natl Acad Sci 108: 557-562.

Menendez D, Inga A, Resnick MA. 2009. The expanding universe of p53 targets. Nat Rev Cancer 9: 724-737.

Meyer KD, Lin SC, Bernecky C, Gao Y, Taatjes DJ. 2010. p53 activates transcription by directing structural shifts in Mediator. Nat Struct Mol Biol 17: 753-760.

Mindell JA, Grigorieff N. 2003. Accurate determination of local defocus and specimen tilt in electron microscopy. I Struct Biol 142: 334-347.

Muhlbacher W, Sainsbury S, Hemann M, Hantsche M, Neyer S, Herzog F, Cramer P. 2014. Conserved architecture of the core RNA polymerase II initiation complex. Nat Commun 5: 4310 .

Murakami K, Tsai KL, Kalisman N, Bushnell DA, Asturias FJ, Kornberg RD. 2015. Structure of an RNA polymerase II preinitiation complex. Proc Nat1 Acad Sci 112: 13543-13548.

Natan E, Baloglu C, Pagel K, Freund SM, Morgner N, Robinson CV, Fersht AR, Joerger AC. 2011. Interaction of the p53 DNA-binding domain with its n-terminal extension modulates the stability of the p53 tetramer. J Mol Biol 409: 358-368.

Neely KE, Hassan AH, Brown CE, Howe L, Workman JL. 2002. Transcription activator interactions with multiple SWI/SNF subunits. Mol Cell Biol 22: 1615-1625.

Nikolov DB, Chen H, Halay ED, Hoffman A, Roeder RG, Burley SK. 1996. Crystal structure of a human TATA box-binding protein/TATA element complex. Proc Natl Acad Sci 93: 4862-4867.

Okorokov AL, Sherman MB, Plisson C, Grinkevich V, Sigmundsson K, Selivanova G, Milner J, Orlova EV. 2006. The structure of p53 tumour suppressor protein reveals the basis for its functional plasticity. EMBO I 25: 5191-5200.

Okuda M, Tanaka A, Satoh M, Mizuta S, Takazawa M, Ohkuma Y, Nishimura Y. 2008. Structural insight into the TFIIE-TFIIH interaction: TFIIE and p53 share the binding region on TFIIH. EMBO I 27: 1161-1171.

Park SI, Borin BN, Martinez-Yamout MA, Dyson HJ. 2011. The client protein p53 adopts a molten globule-like state in the presence of Hsp90. Nat Struct Mol Biol 18: 537-541.

Pettersen EF, Goddard TD, Huang CC, Couch GS, Greenblatt DM, Meng EC, Ferrin TE. 2004. UCSF Chimera-a visualization system for exploratory research and analysis. J Comput Chem 25: 1605-1612.

Pham N, Lucumi A, Cheung N, Viadiu H. 2012. The tetramer of p53 in the absence of DNA forms a relaxed quaternary state. Biochemistry 51: 8053-8055.
Plaschka C, Lariviere L, Wenzeck L, Seizl M, Hemann M, Tegunov D, Petrotchenko EV, Borchers CH, Baumeister W, Herzog F, et al. 2015. Architecture of the RNA polymerase II-Mediator core initiation complex. Nature 518: 376-380.

Ptashne M, Gann A. 1997. Transcriptional activation by recruitment. Nature 386: 569-577.

Radermacher M, Wagenknecht T, Verschoor A, Frank J. 1987. Three-dimensional reconstruction from a single-exposure, random conical tilt series applied to the $50 \mathrm{~S}$ ribosomal subunit of Escherichia coli. J Microsc 146: 113-136.

Revyakin A, Zhang Z, Coleman RA, Li Y, Inouye C, Lucas JK, Park SR, Chu S, Tjian R. 2012. Transcription initiation by human RNA polymerase II visualized at single-molecule resolution. Genes Dev 26: 1691-1702.

Robinson PJ, Trnka MJ, Bushnell DA, Davis RE, Mattei PJ, Burlingame AL, Kornberg RD. 2016. Structure of a complete Mediator-RNA polymerase II pre-initiation complex. Cell 166: $1411-1422$.

Roeder RG. 1996. The role of general initiation factors in transcription by RNA polymerase II. Trends Biochem Sci 21: 327-335.

Scheres SH. 2012. RELION: implementation of a Bayesian approach to cryo-EM structure determination. I Struct Biol 180: 519-530.

Scheres SH. 2015. Semi-automated selection of cryo-EM particles in RELION-1.3. J Struct Biol 189: 114-122.

Sidorenkov I, Komissarova N, Kashlev M. 1998. Crucial role of the RNA:DNA hybrid in the processivity of transcription. Mol Cell 2: 55-64.

Suloway C, Pulokas J, Fellmann D, Cheng A, Guerra F, Quispe J, Stagg S, Potter CS, Carragher B. 2005. Automated molecular microscopy: the new Leginon system. J Struct Biol 151: 41-60.

Tang G, Peng L, Baldwin PR, Mann DS, Jiang W, Rees I, Ludtke SJ. 2007. EMAN2: an extensible image processing suite for electron microscopy. J Struct Biol 157: 38-46.

Triezenberg SJ. 1995. Structure and function of transcriptional activation domains. Curr Opin Genet Dev 5: 190-196.

van Heel M, Harauz G, Orlova EV, Schmidt R, Schatz M. 1996. A new generation of the IMAGIC image processing system. I Struct Biol 116: 17-24.

Wang Y, Rosengarth A, Luecke H. 2007. Structure of the human p53 core domain in the absence of DNA. Acta Crystallogr D Biol Crystallogr 63: 276-281.

Yamaguchi Y, Takagi T, Wada T, Yano K, Furuya A, Sugimoto S, Hasegawa J, Handa H. 1999. NELF, a multisubunit complex containing RD, cooperates with DSIF to repress RNA polymerase II elongation. Cell 97: 41-51. 


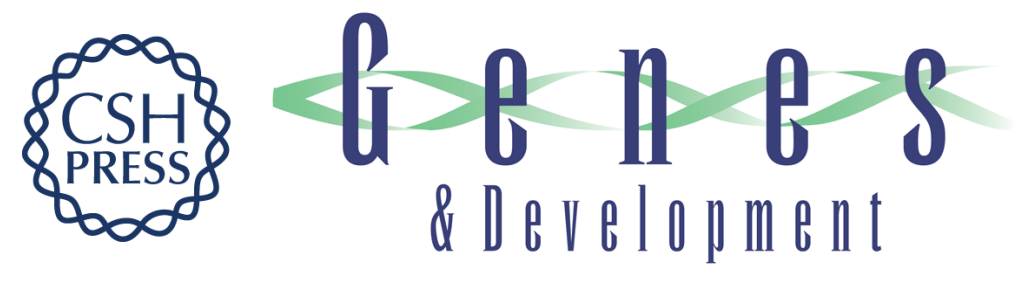

\section{Structural visualization of the p53/RNA polymerase II assembly}

Sameer K. Singh, Zhen Qiao, Lihua Song, et al.

Genes Dev. 2016, 30: originally published online December 5, 2016

Access the most recent version at doi:10.1101/gad.285692.116

Supplemental Material

References

Creative Commons License

Email Alerting Service
http://genesdev.cshlp.org/content/suppl/2016/12/05/gad.285692.116.DC1

This article cites 72 articles, 24 of which can be accessed free at: http://genesdev.cshlp.org/content/30/22/2527.full.html\#ref-list-1

This article is distributed exclusively by Cold Spring Harbor Laboratory Press for the first six months after the full-issue publication date (see

http://genesdev.cshlp.org/site/misc/terms.xhtml). After six months, it is available under a Creative Commons License (Attribution-NonCommercial 4.0 International), as described at http://creativecommons.org/licenses/by-nc/4.0/.

Receive free email alerts when new articles cite this article - sign up in the box at the top right corner of the article or click here.

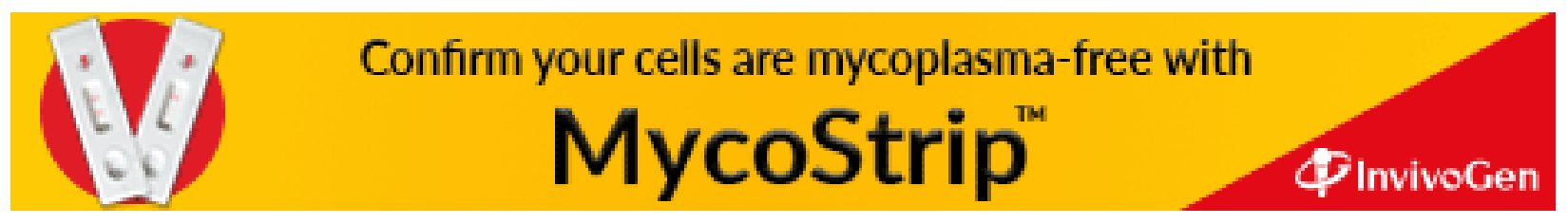

